\title{
Employees' perspectives on strategic human resource development before and after the global financial crisis: evidence from the Greek banking sector
}

\author{
Fotios V. Mitsakis
}

\begin{abstract}
Constantly changing business and economic environments have challenged organizations to re-think the crucial role of their human resource development (HRD) policies and practices in relation to individual and organizational competitiveness, change and growth. Being proactive/strategic, in HRD terms, corresponds to the concept of strategic HRD maturity, a state evidenced by a specific set of strategic characteristics, but research into this concept within the challenging context of the economic crisis is limited, as is research into employees' perceptions of it. Previous research has been applied mostly within 'static' business and economic environments, with much of the existing strategic HRD models neglecting employees' perspectives. Semi-structured interviews were conducted with 42 bank employees in Greece, with the aim of examining their perceptions of strategic HRD before and after the global financial crisis. The study raises important questions for both HRD academics and practitioners because its findings indicate a setback in the development of HRD. Whilst there were a few contradicting perceptions, the dominant employee view was that strategic HRD was a theoretical notion rather than an organizational reality.
\end{abstract}

\section{Introduction}

For most organizations, the 2008 global economic crisis brought forward many human resource development (HRD)-associated concerns. The crisis made them realize the significance of their workforce's development as a means of ensuring business survival and as a way to adapt to ongoing change more effectively (Cascio, 2014; Felstead et al., 2012; Fiksel, 2015; MacKenzie et al., 2012, 2014; McCarthy \& Sheehan, 2014; Sung \& Choi, 2013). The aftermath of the economic crisis affected most banking organizations across the globe, with major restructuring taking place and their HR practices dramatically altered (Mitsakis, 2014a). A recent study from Mitsakis and Aravopoulou (2016) raised concerns about the extent to which strategic HRD (SHRD) is present within organizations under such unfavourable conditions. The authors reported an HRD setback due to the crisis by highlighting its aspirational role within organizations. 
That setback to HRD and a relative lack of exploration of SHRD maturity within the challenging context of economic crisis, added to a neglect of employees' perceptions of it, suggests that further research is required. The rationale behind examining employees' perceptions of SHRD is that it offers an alternative indication of the understanding and maturity of SHRD in organizations beyond that of management. Consistent with the relevant literature, the modified SHRD framework in the present research identifies eight strategic components of SHRD maturity. The framework further allows the consideration of micro and macro environments which can simultaneously constrain or facilitate SHRD. Therefore, it suggests that the employment of the proposed strategic criteria will enhance the HRD function's outlook as an equal strategic business partner, with strategic outcomes to follow. Thus, HRD professionals should be able to constantly demonstrate their value proposition and risk reduction capacity as is often required (Mitsakis, 2014b), and should create dynamic capabilities which can contribute to increased organizational performance and competitive advantage (Garavan et al., 2016).

The contribution of this research lies in the application and testing of a modified SHRD framework within the context of the economic crisis, complemented by its consideration of employees' perceptions of SHRD. The study contributes to academic knowledge by being the first empirical research conducted on SHRD maturity in Greek banks. Thus, it extends a large amount of knowledge within a different national and industrial context, as previous research has been conducted either in the UK or US or under a multi-sectoral focus. The study further adds to academic knowledge by being the first research study applying and testing an SHRD framework within a period of business and economic uncertainty and complexity.

The study also offers managerial implications by highlighting the potential problems and limitations of putting SHRD aspirations into practice, and by highlighting the difficulties of embedding strategic criteria into HRD strategies during periods of dynamic change. The SHRD framework put forward here constitutes a tool for organizations to diagnose their own degree of SHRD maturity by exploring the employment of its strategic components. In addition, it can assist HRD executives to reveal any possible tensions between strategic and operational issues and thus to address all relevant concerns in a more effective manner.

The paper offers a review and critique of the existing SHRD models, followed by the suggestion of a modified SHRD framework. A discussion of the adopted research methodology, data collection methods and analysis, and the research participants is also provided. Then, the paper reports employees' perceptions of SHRD maturity by discussing key data that emerged from interviews. The paper ends with its final conclusions, limitations and recommendations for future research.

\section{Existing strategic HRD maturity models: a critique}

Various SHRD models (Figure 1) suggest how HRD could become strategic in nature, and mature in HRD terms through their respective propositions (Becker et al., 2001; Boudreau \& Ramstad, 2004; Garavan, 1991, 2007; Gilley \& Gilley, 2003; Gilley \& Maycunich, 2000a, 2000b; Lee, 1996; McCracken \& Wallace, 2000a, 2000b; Pfeffer, 1998; Robinson \& Robinson, 2005; Ulrich, 1998).

Garavan (1991) was amongst the first to propose nine key strategic 
characteristics indicating an HRD mature organization. He also proposed that HRD implementations should integrate either vertically or horizontally with corporate objectives. Yet, rather than solely focusing either on a vertical or horizontal integration, the modified SHRD framework suggests for HRD to construct the axis of an organization's life through a multi-dimensional integration (e.g. vertical, horizontal, internal, external).

Later, Lee (1996) made a major contribution in suggesting six layers of SHRD maturity (Figure 2) in relation to the training and development (T\&D) approach that organizations adopt.

\begin{tabular}{|c|c|c|c|c|}
\hline Garavan (1991) & $\begin{array}{c}\text { Torraco \& Swanson } \\
\text { (1995) }\end{array}$ & & Lee $(1996)$ & Pfeffer (1998) \\
\hline $\begin{array}{l}\text { Integration with organizational } \\
\text { missions and goals }\end{array}$ & $\begin{array}{l}\text { Shape business } \\
\text { strategy by }\end{array}$ & \multicolumn{2}{|c|}{ Scale of Training Maturity } & $\begin{array}{l}\text { Create Chief People } \\
\text { Officers by }\end{array}$ \\
\hline Top management support & Being performance based & \multicolumn{2}{|c|}{$\begin{array}{l}\text { 1) Training and learning are } \\
\text { processes through which strategy is } \\
\text { formulated }\end{array}$} & $\begin{array}{l}\text { Building trust through } \\
\text { sharing information and } \\
\text { power }\end{array}$ \\
\hline HRD plans and policies & $\begin{array}{l}\text { Demonstrating strategic } \\
\text { capability. }\end{array}$ & \multicolumn{2}{|c|}{$\begin{array}{l}\text { 2) Training and learning possibilities } \\
\text { help to shape strategy }\end{array}$} & Encouraging change \\
\hline Environmental scanning & $\begin{array}{l}\text { Utilizing employee. } \\
\text { expertise }\end{array}$ & \multicolumn{2}{|c|}{$\begin{array}{l}\text { 3) Training is the means for } \\
\text { implementing corporate strategy } \\
\text { and achieving change }\end{array}$} & $\begin{array}{l}\text { Measuring key drivers of: } \\
\text { success }\end{array}$ \\
\hline $\begin{array}{l}\text { Line Managers commitment \& } \\
\text { involvement }\end{array}$ & & \multicolumn{2}{|c|}{$\begin{array}{l}\text { 4) Training integrated with } \\
\text { operational management }\end{array}$} & \\
\hline Complementary HRM activities & & \multicolumn{2}{|c|}{ 5) Isolated tactical training } & \\
\hline Recognition of culture: & & \multicolumn{2}{|c|}{ 6) No systematic training } & \\
\hline \multicolumn{5}{|l|}{ Emphasis on evaluation } \\
\hline Uirich (1998) & \multicolumn{2}{|c|}{$\begin{array}{l}\text { McCracken \& Wallace } \\
(2000 \mathrm{a}, 2000 \mathrm{~b})\end{array}$} & Dwyer (2000) & $\begin{array}{c}\text { Gilley \& Maycunich } \\
(2000 \mathrm{a}, 2000 \mathrm{~b})\end{array}$ \\
\hline $\begin{array}{l}\text { Partner with senior and line } \\
\text { management }\end{array}$ & \multicolumn{2}{|c|}{$\begin{array}{l}\text { Shaping organizational missions } \\
\text { and goals }\end{array}$} & $\begin{array}{l}\text { Measure perfommance in } \\
\text { quant fiable tems } \& \\
\text { osmmunicate impact of } \\
\text { long-term human capital. } \\
\text { investments }\end{array}$ & $\begin{array}{l}\text { Focus on: } \\
\text { Organizational Learning } \\
\text { Organizational } \\
\text { Perfommance } \\
\text { Organizational change. }\end{array}$ \\
\hline $\begin{array}{l}\text { Be experts in how work is } \\
\text { organised and executed }\end{array}$ & \multicolumn{2}{|c|}{ Top manegement leadership } & $\begin{array}{l}\text { Know micro \& } \\
\text { macroeconomio political } \\
\text { \& social realities }\end{array}$ & $\begin{array}{l}\text { Domains } \\
\text { Analysis } \\
\text { Deslgn of initiatives a } \\
\text { interventions } \\
\text { Evalustion }\end{array}$ \\
\hline Be a champion for employees. & \multicolumn{2}{|c|}{$\begin{array}{l}\text { Environmental scanning by } \\
\text { senior management; in HRD } \\
\text { terms }\end{array}$} & $\begin{array}{l}\text { Investigate business } \\
\text { needs \& drive sction } \\
\text { essential to business } \\
\text { muocest. }\end{array}$ & $\begin{array}{l}\text { Elernents } \\
\text { HRD transformation } \\
\text { HRD leadership } \\
\text { Prindiples of strategio } \\
\text { HRD: }\end{array}$ \\
\hline \multirow[t]{6}{*}{$\begin{array}{l}\text { Be a champion for oontinual } \\
\text { organizational transformation }\end{array}$} & \multicolumn{2}{|c|}{ HRD strategies polidies \& plaris } & & \\
\hline & \multicolumn{2}{|c|}{$\begin{array}{l}\text { Strategic partherships with line } \\
\text { management: }\end{array}$} & & \\
\hline & \multicolumn{2}{|c|}{ Strategio partnerships with HRM. } & & \\
\hline & \multicolumn{2}{|l|}{$\begin{array}{l}\text { Trainers as organizational } \\
\text { change oonsultanits }\end{array}$} & & \\
\hline & \multicolumn{2}{|c|}{ Ability to influence corp. culture } & & \\
\hline & \multicolumn{2}{|c|}{$\begin{array}{l}\text { Emphasis on oost-effectiveness } \\
\text { evaluation }\end{array}$} & & \\
\hline $\begin{array}{l}\text { Becker, Huselid \& Uirich } \\
(2001)\end{array}$ & \multicolumn{2}{|c|}{ Gilley \& Gilley (2003) } & $\begin{array}{c}\text { Boudreau \& } \\
\text { Ramstad (2004) }\end{array}$ & $\begin{array}{c}\text { Robinson \& } \\
\text { Robinison (2005) }\end{array}$ \\
\hline \multirow[t]{3}{*}{$\begin{array}{l}\text { Develop rigorous } \\
\text { megsurement systemis: }\end{array}$} & \multicolumn{2}{|c|}{$\begin{array}{l}\text { Domains } \\
\text { Organizational Learning } \\
\text { Organizational performance } \\
\text { Organizationsl change }\end{array}$} & $\begin{array}{l}\text { Human Capacity } \\
\text { Bridge Framework }\end{array}$ & $\begin{array}{l}\text { Build client } \\
\text { partnership } \\
\text { Acoess } \\
\text { Oredibility } \\
\text { Trust }\end{array}$ \\
\hline & \multicolumn{2}{|c|}{$\begin{array}{l}\text { Steps: } \\
\text { Communicate urgency for } \\
\text { ohsmge } \\
\text { Provide leadership } \\
\text { Create ovninership } \\
\text { Implement } \\
\text { Integrate change into org; culture } \\
\text { Megsure progress }\end{array}$} & $\begin{array}{l}\text { Anchor Points: } \\
\text { Impact } \\
\text { Effectiveness: } \\
\text { Efficiency: }\end{array}$ & $\begin{array}{l}\text { Identify \& partner to } \\
\text { suppoirt projects } \\
\text { Reframe requests } \\
\text { Prosoctively identify } \\
\text { strategio oppoitunities } \\
\text { Implement projects }\end{array}$ \\
\hline & \multicolumn{2}{|c|}{$\begin{array}{l}\text { Result } \\
\text { Successful transformation of } \\
\text { HRD }\end{array}$} & $\begin{array}{l}\text { Linking Elements } \\
\text { Sustainable strategio: } \\
\text { suocess, Resources \& } \\
\text { process, Talent pools } \\
\text { Aligined actions } \\
\text { Human capsoity } \\
\text { Policies \& practides. } \\
\text { Investrnenty }\end{array}$ & $\begin{array}{l}\text { Influence business } \\
\text { strategies and } \\
\text { direction } \\
\text { Contribute to formation } \\
\text { of plans. } \\
\text { Integrate HR strategio } \\
\text { plan into business plan } \\
\text { Implement people } \\
\text { initiatives. }\end{array}$ \\
\hline
\end{tabular}

Figure 1: SHRD models. 


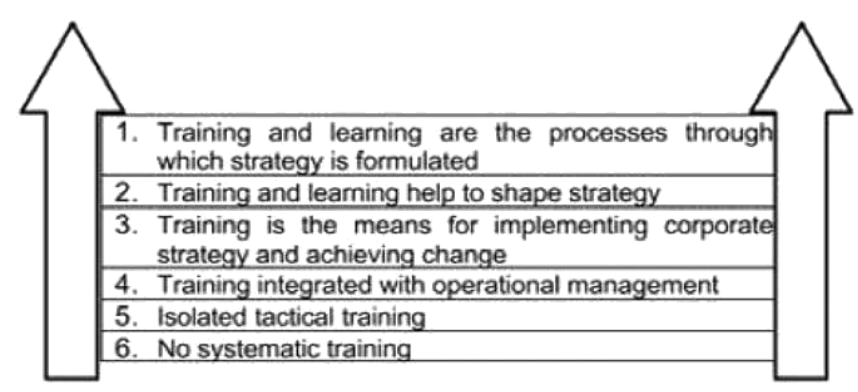

Figure 2: Scale of training maturity (Lee, 1996).

The author categorized them based on the degree of their strategic integration with the corporate strategy. Therefore, moving from the lower to the upper levels, organizations become more mature, with their HRD practices being more likely to shape and influence organizational strategy and objectives. However, the model neglects other important HRD practices (e.g. career planning, change management, appraisals, evaluation, etc.), which can also affect HRD's strategic integration and alignment with business practices and SHRD maturity, respectively (Pfeffer, 1998; Ulrich, 1998). Furthermore, the model's sole focus on the sophistication of training ('the degree of their strategic integration with the corporate strategy') was proved problematic as the intensity of training cannot guarantee enough evidence of an organization's SHRD maturity. Therefore, specific indicators of SHRD maturity were proposed (Figure 5).

Later, Pfeffer (1998) argued that it is through greater HRD interventions that its role, effectiveness and contribution can be strengthened. However, a critique that accompanies this model concerns its suggestion of 'driving change', as not all change is necessarily strategic. In addition, similar to Garavan's (1991) model, both implied a short-term, financial-driven and responsive HRD evaluation process.

McCracken and Wallace (2000a, 2000b) suggested a new framework to advance the SHRD maturity by arguing that all strategic criteria should be integrated and interrelated so as to promote a learning culture within organizations. The model offers many interesting suggestions (e.g. HRD to shape organizational missions and goals, strategic partnership with HRM, active involvement of line managers, etc.), most of which are fully embraced by the modified SHRD framework. However, the model's emphasis on cost-effective HRD evaluation implies a shortterm orientation through the achievement of financial business results and cost control, rather than focusing on long-term strategic outcomes such as individual and organizational change and knowledge transfer to job contexts. In addition, the extent to which the authors' suggestions are realistic or not under the challenging context of an economic crisis and its aftermath is a matter of debate. Thus, the modified SHRD framework aims at evaluating the nature, change and constraints of SHRD, and to examine the difficulties of putting SHRD aspirations into practice under periods of business and economic uncertainty and complexity.

Following the SHRD discourse, Gilley and Maycunich (2000a) proposed that organizational learning, performance and change can constitute the key criteria of an HRD mature organization, through a three-step process (analysis, design of interventions and evaluation) in measuring their effectiveness. However, such practices can be viewed as just common HRD actions. Although the authors introduced another three elements (e.g. HRD transformation, leadership and principles of SHRD) that can influence these practices, they did not fully explain 
how to test the extent to which these elements, domains and practices can help HRD in becoming strategic. Therefore, Gilley and Gilley (2003) repositioned SHRD by suggesting a seven-step process through which organizations can increase their HRD strategic positioning. Although the model aptly recognizes specific HRD behaviours (e.g. leadership, ownership, shared vision, change management, etc.) which can be translated into specific objectives, their proposition remains vague as to how all these elements are interconnected, and as to how these behaviours could be viewed as strategic rather than simply being operational and reactive in nature. Overall, the model focuses more on how to drive change (not all change is necessarily strategic) rather than presenting the ways in which HRD could achieve a proactive and more influential role within organizations.

Boudreau and Ramstad (2004) suggested their 'Human Capacity Bridge Framework', by promoting a connection among the anchor points of the model and its linking elements. By narrowly focusing on identifying those areas in which talented workforce has the greatest impact, and by creating a pool of highly talented employees who drive business results, the authors advocated for their framework's appropriateness in help-ing HRD to become a pivotal player in organizations. However, the model does not consider other potentially influential factors (macro and micro-environmental forces) that can also affect HRD's strategic outlook. Therefore, Robinson and Robinson's (2005) model outlined the imperative need for HRD to become a strategic business partner within organizations. The authors proposed three main HRD accountabilities (building client partnerships, identifying and partnering to support projects, influencing business strategies and direction) through which HRD can become strategicoriented. Such suggestions constitute the central idea of the modified SHRD framework within its strategic propositions (e.g. strategic partnerships with senior executives, branch managers (line managers) and employees, shaping organizational missions, goals and strategies, strategic partnership with HRM, etc.). Further to that, the authors' suggestion to view HRD as an equally strategic business partner is also highly welcomed.

Lastly, Garavan's (2007) SHRD model suggests that HRD strategies and practices should focus on achieving performative outcomes, the creation of a learning culture and the facilitation of the organizational change process. The model can be characterized as the most complete one by recognizing that several conditions (e.g. local, national, multinational, etc.) can affect the organizational contexts and stakeholders' expectations (Figure 3).

However, it can be criticized for adding too many dimensions that can make SHRD's understanding extremely complex. Its extensive internal and external dimensions (24 processes) and their expected outcomes (14 outcomes) also constitute a model that may be challenging to operationalize and test. Lately, Garavan et al. (2016) suggested a conceptual framework examining how SHRD contributes to organizational performance and competitive advantage through developing dynamic capabilities. Consistent with the authors' suggestions, the modified SHRD framework suggests for HRD strategies, plans and policies to be 'environmentally integrated' so as to respond to business and economic uncertainty.

Overall, it is difficult for HRD to be 'put into a box'. It is quite difficult as well to assess to whom the call for SHRD is directed, as different stakeholders, in facing a similar situation, would react differently by taking diverse strategic decisions. 
Coupled with the relative lack of empirical studies testing SHRD models' application within the context of an economic crisis, and their lack of addressing employee advocacy, this study aims at addressing these concerns. Therefore, the modified SHRD framework has been applied under the challenging context of the economic crisis, along with taking into consideration employees' advocacy towards its strategic propositions.

\section{Towards a modified SHRD framework measuring SHRD maturity}

The study aimed at examining the extent to which specific strategic criteria were embedded within both case study organizations so as to evaluate the state of maturity of their SHRD practices over time. To address its aim, the following research question was framed:

How strategic have HRD practices been within these two banking organizations from employees' perspectives, and over the period of the recent economic crisis and its aftermath? 


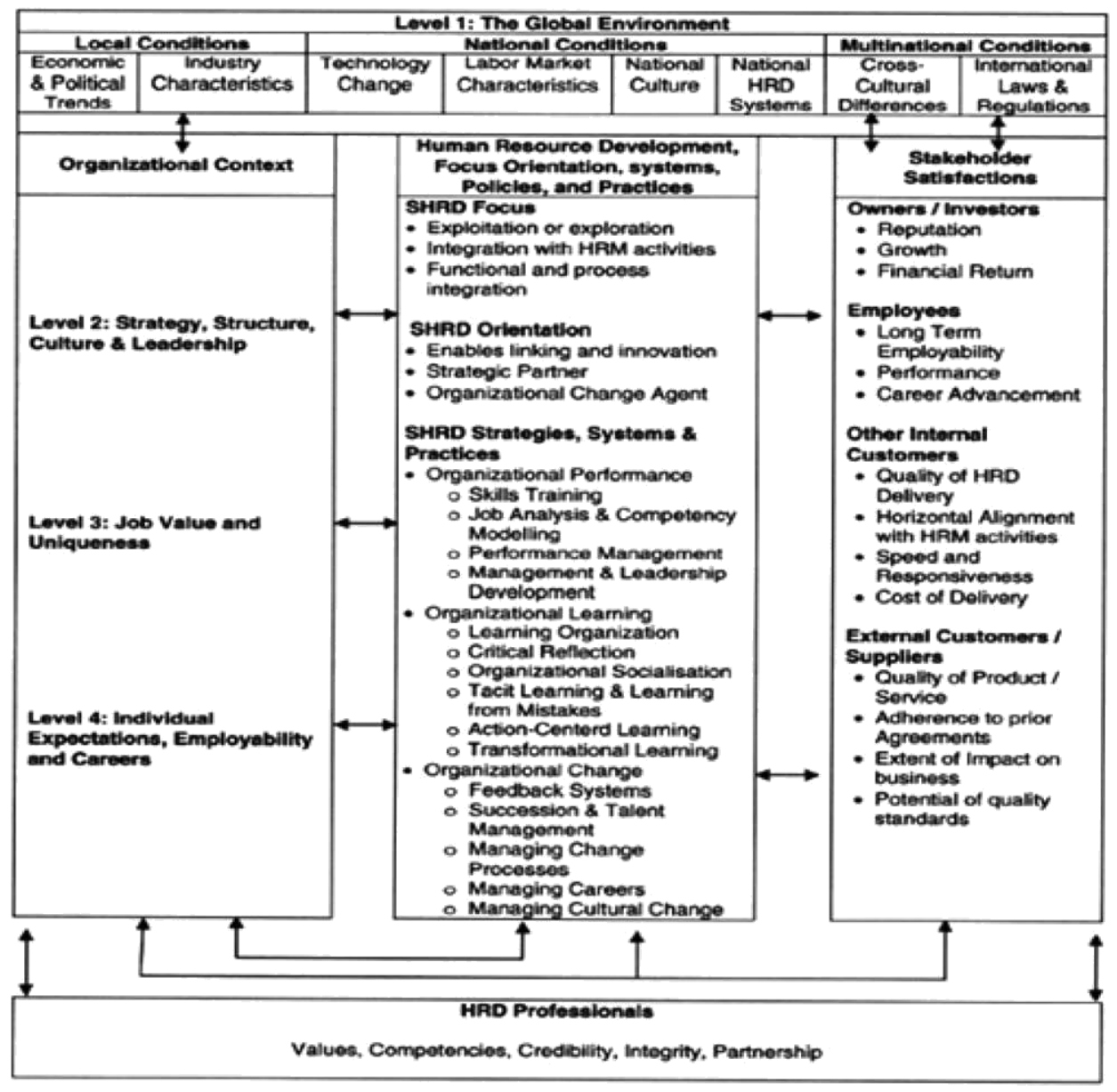

Figure 3: Garavan's SHRD model.

The study built upon the most comprehensive and cited SHRD model within the literature (that of McCracken \& Wallace, 2000a, 2000b) in order to put forward a modified SHRD framework (Figure 4) aiming at enhancing the authors' work in such a way as to advance the notion of SHRD maturity through the suggestion of a slightly modified cluster of strategic criteria. Drawing upon McCracken and Wallace's (2000b) SHRD maturity definition ('strong evidence of the SHRD characteristics', p. 435), the concept was re-defined as 'the presence of strong or weak evidence of the suggested strategic criteria, and of their respective indicators, of the modified SHRD framework'.

The modified SHRD framework addresses previous models' limitations through its strategic components. It moves away from vague notions such as that of 'learning organization' and 'driving change', as not all change is strategic, while power-related concerns are ignored within learning organizations (Valentin, 2006). Instead, it proposes for SHRD to attain a strategic business-partnering role within organizations in order for strategic outcomes to emerge.

The modified SHRD framework incorporates employees as key stakeholders while forming strategic partnerships, while a more strategic-oriented evaluation is also pro-posed compared to a reactive, financial-driven and short-term one within previous SHRD models. The framework further suggests for HRD practices to be 'environmentally integrated' so as to offer a constant evaluation of both internal and external con-textual factors and thus to respond effectively to business 
uncertainty and complexity.

\section{Modified framework of SHRD Maturity}

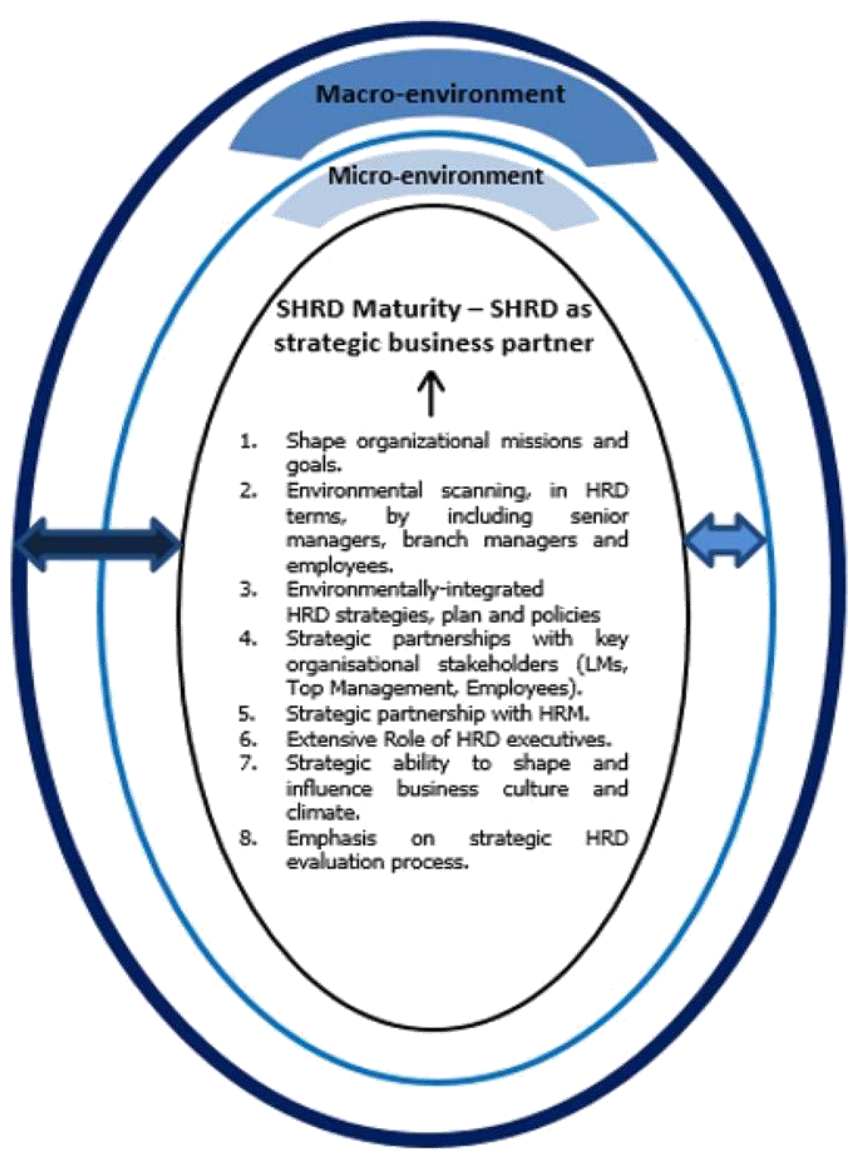

Figure 4: A modified SHRD framework measuring SHRD maturity. 
In addition, both the micro and macro environments are considered as potential influential factors on SHRD maturity, yet without constituting the central point within this research study. Finally, the modified SHRD framework suggests that there is a strong interrelation between all strategic characteristics without amplifying one to the exclusion of the other, even if the emphasis given to each may vary over time. Therefore, all are equally weighted with regard to SHRD maturity.

Taking all these into consideration, the modified SHRD framework was tested pre and post the global financial crisis so as to identify the nature, change and constraints of SHRD, along with examining the potential problems and limitations of putting SHRD's aspirations into practice within dynamic periods of business and economic uncertainty. To facilitate the testing of the SHRD framework, specific indicators of SHRD maturity (Figure 5) were proposed for each of the strategic characteristics. Therefore, building upon Lee's (1996) idea of creating a scale of SHRD maturity, the respective indicators allowed the researcher to propose key elements for each one of the suggested strategic components of his SHRD framework. Eventually, two potential states of SHRD maturity can be identified, namely the mature and immature state.

These were initially developed before the interviews, but were updated throughout and after their completion. Based upon employees' responses, a decision was taken over the strength of the evidence provided for each respective strategic criterion and in accordance with those key indicators for each strategic component. HRD academics are welcomed to use both the modified SHRD framework and its strategic indicators table so as to further test them in different business and national contexts. Both could also prove important to HRD practitioners in monitoring the state of SHRD maturity in their organizations and as a benchmark tool to analyse their competitors' SHRD approach. 


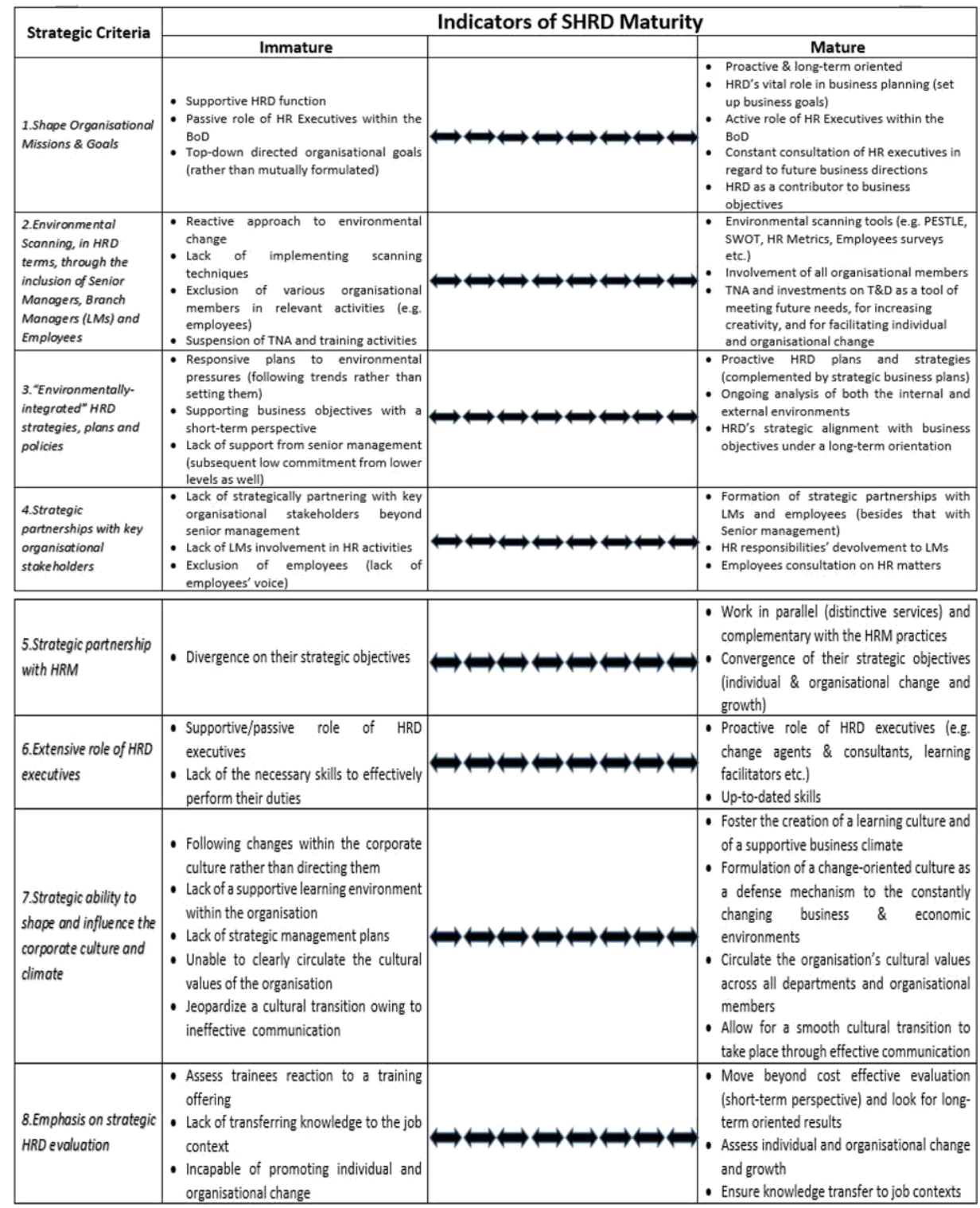

Figure 5: Indicators of SHRD maturity.

\section{Research methodology and participants}

Research data were secured through qualitative research and the employment of a case study research strategy. The population of this research is defined as the Greek bank-ing sector and its employees. However, due to time and access constraints, it was not possible to examine all banking institutions within the sector, nor to interview all potential stakeholders. Therefore, the researcher chose to focus on two banking organizations (those reporting major restructuring), and to conduct interviews with employees with more than 6 years of service so as to address interview questions retrospectively. Yet, the researcher acknowledges that the decision not to approach all banks and other potential stakeholders may constitute a limitation on the study's ability to present a more holistic view of the phenomenon under investigation. 
Following previous SHRD models' lack of assessing employees' perceptions, most of the research participants were front-line employees owing to a business focus shift identified, during preliminary research, towards the enhancement of their front-line operations. Therefore, 15 employees were interviewed in 'Case A', and another 16 in 'Case B'. In addition, five employees (from other corporate divisions) also participated ('Case A'), along with six from 'Case B'. In total, 42 employees offered their perceptions of SHRD.

The researcher approached bank employees through his personal network, supported by snowball sampling. Such a technique allows recommendations of additional interviewees from existing ones. Having clearly explained the purpose of the study to all, he assured that all participants held the desired knowledge to offer robust evidence on the discussed themes (strategic criteria) so as to enhance the research outcomes.

\section{Data collection methods}

Semi-structured interviews were also conducted. These took place in the summer of 2014 (July-September), with most of them conducted within both banks' branches and their headquarters. However, a few interviews were performed in a 'neutral' quiet environment outside the organizations, as participants wanted to ensure anonymity. Many of the interviews were conducted in Greek as per participants' requirement. All concepts were clearly explained, while interviews were transcribed and translated into English by the researcher so as to reflect the actual meaning of the participants' responses. Most interviews lasted from 60 to $90 \mathrm{~min}$, while digital recordings were safely backed up onto two different external data storage devices for security purposes and future use.

Concerning the ethical considerations of this research, an 'Ethics application form', and a 'Context form' were given to all interviewees. Both documents highlighted that all personal data would remain strictly confidential and would be destroyed upon completion of the research. Thus, research participants and the case study banking organizations' confidentiality and anonymity were assured. Finally, the researcher offered the opportunity to organizations to acquire a brief report on the final findings as the minimum return for allowing their employees to participate.

\section{Data analysis}

Research data from interviews were carefully transcribed, and grouped under specific sections following the analysis of pre-determined key themes (e.g. strategic characteristics). Data analysis was carried out during the fieldwork by constantly analysing, cod-ing and explaining all interview notes. Short code names were also given to all interview participants (e.g. branch network employee, 'EmpBN'; and employee - corporate division, 'EmpCD', etc.).

Research data and findings were further analysed using a thematic analysis approach by focusing on the strategic characteristics of the modified SHRD framework. Finally, research data were analysed through a before-and-after research investigation design (pre- and post-crisis) in order to highlight the nature, change and constraints of SHRD under a period of business and economic turbulence. Having employees retrospectively address all interview questions might increase the possibility of them recall-ing the 'golden age' times of the 
prosperous past though, leading invalid conclusions being drawn. However, the researcher triangulated interview data with various organizational documents to crosscheck interviewees' responses.

\section{Results: employees' perceptions of the suggested strategic characteristics (SHRD framework)}

Employees' perspectives indicated the way in which SHRD was understood and operationalized within their respective organizations, along with highlighting the extent to which the strategic criteria were embedded within their organizations' HRD strategies, plans and policies.

Ability to shape organizational mission, goals and strategies

It is widely argued that HRD's strategic outlook could be assessed through the way in which its voice is expressed and heard during corporate strategy's formulation (Garavan, 2007; Holbeche, 2009; Mitsakis, 2014b; Sung \& Choi, 2013). Therefore, employees offered their opinion on HRD's ability to do so.

A large majority of them (Case A) suggested that HR always lacked the capacity to influence and shape organizational objectives, as everything was directed from senior management. They argued that its role is restricted (either before or after the crisis) to following top-down guidelines, and accordingly in supporting their successful implementation. They further noted that their organization's retrenchment strategy impeded HRD's strategic implementation with major budget restrictions to be recorded.

They further claimed that although a more proactive role is required for HRD these days, its setback is clear. With all that considered, they could not identify a match between SHRD and their bank's HRD approach. Having been asked to highlight the major problems associated with the strategic development of their HRD practices all outlined its lack of a strategic business focus, by arguing that:

What you are talking about is more of an old fairy tale with a bad end. There is no long-term strategy, while a limited budget is now available for almost all business functions; our HR department does not hold the capacity to design and deliver substantial developmental opportunities, as its first priority is to keep costs down through major staff redundancies and other related actions. Don't think that makes it strategic at all. (EmpBN1)

Today, there is no HR planning, especially under a long-term perspective. All business executives, along with those in HR, are occupied with how to increase short-term business prosperity through the latest business amalgamations. What they forget is that people make the difference; employees are those keeping banks operating. (EmpCD1)

Evidently, their viewpoints illustrate HRD's inability to shape organizational strategies due to its functional, cost and short-term orientation. Most of them argued that their HR department (including its HRD staff) has always been reactive in nature rather than demonstrating its strategic value proposition.

The story, however, was reported differently for the period before the crisis. All employees (Case A) highlighted that greater HRD opportunities were offered back then, either because of the bank's expansion or due to favourable economic and industrial conditions. Thus, they argued that: 
In the past, you could choose amongst a wide range of training opportunities to undertake either within the bank's training centre or through its training associates. Today, limited training sessions are offered as subsidized programmes from the Manpower Employment Organisation, with limited support offered from our managers. (EmpBN2)

Training is mainly focused on front-line employees, with the rest of us to be left responsible for our own development. Cost minimization dictates the provision of targeted training to specific business sections. There is no point of talking about career development opportunities, promotions etc. (EmpCD2)

Both agreed that today's training opportunities are mainly offered to those employees most in need of them (branch network). Largely, that may constitute partial evidence of a strategic alignment between HRD and business objectives, yet without clearly indicating the extent to which the former can shape and influence the latter.

'Case B' employees' perceptions of SHRD matched those of their colleagues from 'Case A'. Initially, all argued that staff shortages within the HR department resulted in overloading existing staff with greater work responsibilities, thus making them incapable of performing to their highest standards. HRD implementations have also been affected, which now seem to be improperly designed and delivered; thus making them ineffective. Therefore, employees argued that HR can no longer shape business objectives as senior management directs strategies:

We can no longer talk of SHRD when the organization fights for its daily survival. The bank aims to maintain its customer base, quite a short-term financial approach indeed, however by totally neglecting its people's capacity to do so. (EmpBN1)

I guess we do have an HRD strategy. At least, it is evident within all of our organizational documents. Yet, that does not mean that our HRD strategy can formulate the bank's mission, goals and strategies. This is impossible. Do not ever believe that HR will reach this extent especially within these days we live. (EmpBN2)

Limited HR initiatives are now offered, compared to the past, indicating the organization's main focus on reducing costs. Therefore, which strategic goals are you talking about? What they call strategic HR/HRD approach (cut down HR expenditures) only reflects business's cost-down orientation. In that case, HR's sole input in the strategy formulation process is to help implement it. (EmpCD1)

If HRD executives ever held the capacity to shape business strategies, then more training and developmental opportunities would have been offered. Instead, limited training is provided today, and in many cases on very irrelevant subjects. That was not happening in the past. (EmpCD2)

From those employees' viewpoints, a reactive role of HRD is evident. As per their 'Case A' colleagues, they believed that HR always lacked the ability to shape business objectives and strategies, and that can be seen through its limited HRD offerings. Largely, they have associated HRD's effectiveness in shaping business 
goals and strategies with the volume of their bank's training offerings, by reporting on their HR department's role:

We feel like the pawns in a chess match [the first casualties], not to mention that our opinion does not count. But you know what? Their opinion [HR] does not count either. Business decisions are directed from senior executives, and forwarded to business unit managers accordingly. These are the people shaping our business strategy and objectives and, accordingly, the focus of HRD. (EmpBN3 - Case A)

Hopefully someday, everybody will understand how important it is to keep your employees satisfied, motivated and valued during such difficult times. If our HR department realize that, then it will be able to drive our organizational goals and strategies towards such a direction. (EmpCD3 - Case B)

However, two employees acknowledged that the organization is under a transitional phase, and thus time will be required before making their final judgements on people and departments concerning their effectiveness. Although all have agreed that greater training opportunities were offered in the past, this could not indicate HRD's ability to shape business strategies. For them, business growth was seen as the sole explanation of higher training budgets, as their organization had to provide more induction and follow-up training to newcomers and existing employees, respectively.

Overall, research evidence was stronger on HRD's ability to influence business strategies and goals for the period before the crisis. On its post-crisis status, however, employees identified that there was a 'setback' for HRD within the business agenda by arguing that its role was limited to the basics. They also appeared sceptical as to whether HR's positioning within the Board of Directors was of great importance, as the department was, is and will be the most marginalized in terms of budget allocations. Yet, a few stated that time will be needed before judging people and departments with regard to their efficiency. Evidently, employees offered an operational viewpoint that might be the result of their lack of relevant information to holistically assess the ability of their HRD practices to meet this specific strategic criteria.

\section{Environmental scanning, in HRD terms, through the inclusion of senior managers, branch managers and employees}

Research evidence highlights that relevant scanning activities are limited, and mainly conducted only by senior executives and their teams. Employees' lack of involvement was outlined in both case studies. Precisely, 'Case A' employees argued:

We cannot recall ever being asked for anything relating to our workplace. (EmpCD4)

We, either individually or collectively, have never participated in such actions; I assume it was the work of our managers to do so, but I am not sure whether they did it either. (EmpBN4)

Although most interviewees stressed their non-participation in any environmental scanning activity, there were also a few (2-3 employees) who 
recalled various 'employee surveys' undertaken in the past to ask for their opinion on various organizational concerns. However, a striking observation emerged from five employees' perceptions of not feeling competent enough to do so due to a lack of relevant information. Whether this is an outcome of trade unions' lack of representation and/or the result of their 'ignorance' is up for debate.

In a similar vein, 'Case B' employees were excluded from relevant scanning activities. Although they recalled several past employee surveys, they could not say to what extent their involvement was above the basic level. Thus 17 employees suggested that they do not necessarily need to be advised on such issues, as it is their managers' concern to do so. Indicatively, a branch employee suggested:

It is not our job to do so; otherwise, we would have been called managers or top executives. Even with regards to the surveys we complete, their points do not relate to strategic issues. (EmpBN3)

Contrary to the SHRD framework's suggestion, weak evidence was provided on employees' participation in scanning activities, and mainly pre-crisis. Employees were not invited to participate, as it was believed that their limited access to information could restrict their strategic insight. Stronger evidence was provided though from all participants concerning pre-crisis environmental scanning, mainly as an outcome of both banks' growth strategies. Overall, employees' responses out-line their lack of involvement and an overall perception of a setback for HRD. Accordingly, SHRD maturity moves towards an immature state within the respective strategic indicators table, with a slightly better state to be noticed for the period before the crisis.

\section{'Environmentally integrated’ HRD strategies, plans and policies}

Having 'environmentally integrated' HRD strategies in place could form the basis of an organization's competitive advantage (resource-based HR - Chuang \& Lin, 2016), along with increasing HR strategy's efficiency (best-fit HR - Marchington \& Grugulis, 2000), and enhancing organizational performance (best-practice HR - Marchington \& Grugulis, 2000).

All employees in 'Case A' stressed that HR always lacked the ability to exploit environmental challenges, as its main concern was on supporting the business rather than indicating future directions. Precisely, an employee illustrated his colleague's assertion by stating:

Today, HR is like a 'water-boy' within a sports team. The latter needs to be constantly hydrated, with the former's role to provide team members with refreshments; however, team players can live without him, as his job is not that difficult as to require special skills. (EmpBN5)

Quite similarly, all 'Case B' employees suggested that HR/HRD had lost its position within the business agenda. They argued that either before or after the crisis HR/ HRD's aim was to 'get more by doing less'. Their assertion clearly outlines their belief that their organization's HR practices were always implemented in such a way as to ensure that through limited costs the optimum outcome will be returned. Such beliefs can be evidenced through two employees' statements: 
directions, instead of pro-actively being involved in their formation. From your definition of a HRD mature organization, I will only keep the cost-efficiency perspective. (EmpBN6)

Keep costs down, do only what is necessary, and get the most from your implementations. That is our HR philosophy. If that makes a highly sophisticated HR organization, then I would say that we are mature enough, since the only thing the entire business does is to keep costs down by any means. (EmpCD5)

Most employees (from both cases - 33 out of 42) also argued for the inappropriateness of e-learning and the irrelevance of the training subjects by stating:

Yes, apparently we all live in the so-called information age, yet not all of us have a high level of PC literacy. Because of that, class-based training seems better - nonetheless to highlight the interaction between the trainer and the trainee. Our bank distinguishes important from non-important training depending on how much it costs. Although some HRD initiatives are relevant to us, they are not implemented because of being considered expensive. (EmpBN4 - Case B)

It is pointless to get training either in totally irrelevant subjects (e.g. first aid) or by attending extensive e-based seminars which do not address our actual needs. E-courses and webinars are promoted as high-quality training techniques these days, yet the underlining reason behind such implementations is simple: cost efficiency. (EmpCD6 - Case A)

However, there were a few employees (3-4, Case B) who identified e-learning and webinars as the most effective training approaches during such lean times.

Overall, the implementation of targeted training (e-learning, etc.) could be viewed as a best-fit HR solution to meet new business realities. Without arguing for or against their short-term orientation, the delivered HRD interventions, from both organizations, seem to have been quickly enacted and at a relatively low cost, while maintaining an organizational fit with its external environment. Yet, employees' perceptions of it are different. Therefore, the extent to which both organizations had presented high preparedness towards business and economic uncertainty is controversial, and makes SHRD maturity's evaluation difficult with regard to this strategic criterion. Accordingly, HRD executives' role becomes more complicated as to how to cope better with business and economic uncertainty and complexity.

\section{Strategic partnerships with key organizational stakeholders}

Research evidence highlights that such partnerships are attained only between HR and senior executives, and with branch managers in some cases, yet without the employees.

Most employees (Case A) underlined HR/HRD's lack of strategic vision and voice, as guidelines are mostly dictated from the top and expected to be strictly followed. Thus, they suggested that their consultation, within any HR/HRD initiative, seems pointless. Additionally, they argued that the limited training being offered is not the outcome of a proper training needs identification mechanism as 
it used to be in the past. Thus, they argued:

In the past, the HR department used to conduct a quarterly employee survey through which train-ing needs were identified and training interventions were designed and delivered. Today, such surveys are rarely conducted, or not at all, while training does not reflect our actual needs and/or focuses on totally irrelevant things. (EmpCD8)

I cannot understand how a 'health \& safety' course can enhance my knowledge and productivity or keep me motivated. Supposing that business focus is now on front-line operations, we have no voice at all. (EmpBN7)

All further suggested that an evident HR failure of strategically collaborating with them could restrict those organizational efforts aimed at developing targeted HRD interventions to maximize employees' quality of customer service delivery. Many (18 out of 22) further highlighted that their managers do not communicate and promote training and career advancement opportunities to them as well, by arguing:

Our managers' role is inhibited in simply reporting their branch's monthly results to superiors, while ensuring that guidelines are closely followed. Not any input on training and development concerns. (EmpBN8)

Similar to their 'Case A' colleagues, all employees (Case B) highlighted that their voice is not heard as they are the most 'vulnerable organizational assets' these days. Thus, their consultation is of limited importance:

With so many staff redundancies, how can we expect to be heard? Everyone ignores us. Just have a look on the training deliveries and you will realize that they do not care about us. Rather than trying to address our actual training needs, they deliver irrelevant to our job contexts training. That's their approach to keep us motivated and developed. (EmpBN5)

You know what? If we are about to fall, we will all fall. If we want to succeed in what we do, everyone should contribute regardless of his/her position within the organization. Yet, they take the decisions and they blame others if something goes wrong. We are either all together or not. (EmpCD4)

Overall, everyone seemed sceptical towards their HR departments' implementations, while they have also questioned if the implemented HRD interventions reflected their actual needs. Employees also reported miscommunication problems by arguing that in many cases they do not even get any feedback or evaluation after completing a training course. Further to that, they suggested that their lack of voice could impede their HR department's efforts to design and deliver targeted practices to maximize operational effectiveness. Opposite to what is suggested by the modified SHRD framework, both organizations totally excluded their employees from such strategic partnerships. Ultimately, that could indicate both banks' immature state in relation to this specific strategic component.

\section{Strategic partnership with HRM}

Research evidence could not clearly indicate whether such a partnership exists or 
not, as employees' perspectives on this specific strategic criterion could not offer clear insights. Not all employees (Case A) could distinguish between HRM and HRD, by collectively arguing that both are delivered under the umbrella of the general HR practices:

HRM, HRD, what's the difference? It's only one letter. What is the same is HR's retrenchment. (EmpBN9)

I can't recall the last time I have been offered a training opportunity. It was probably back in 2009, just before the crisis commenced. I assumed people in front-line operations now get the most training as now banks try to ensure their survival through their retail operations. (EmpCD7)

However, things presented differently before the crisis, when a more enhanced role for the HRD function was evidenced through a higher budget allocation. Yet, employees suggested that its initiatives were still implemented under the HRM umbrella.

Employees (Case B) have also referred to the volume and the nature of the training offered before and after the crisis by suggesting:

HRM-HRD, who really cares? In the past, greater training opportunities were offered to all. Nowadays, limited training is provided, and it is targeted at specific employees. Being one of them, I can't see the point though as to how a first aid training or an environmental consciousness programme can increase my productivity. (EmpBN6)

I think that my organization offers the minimal training required for keeping us satisfied (somehow); yet, I don't think it manages to do that, especially within such a turbulent business environment and through its practices. (EmpCD5)

Once more, employees' perceptions mainly focused on the intensity and the subject of the training provided, and thus they have judged HR's effectiveness upon those two dimensions. Yet, employees' perceptions cannot clearly indicate the extent to which this specific criterion had been met.

\section{Extensive role for HRD executives}

Research evidence highlights employees' unified perceptions of the importance of HRD executives to undertake a more influential role within the business. Most of them further acknowledged that HRD's pre-crisis role allowed both its executives, and the organization as a whole, to achieve this objective.

However, although recognizing that as an important element, all employees (Case A) stressed their HR department's ineffectiveness owing to staff shortages and the lack of relevant skills from those that remained, by arguing:

Our HR department is experiencing staff shortages and/or a relative lack of those skills required to efficiently perform its duties and to deliver exceptional services. (EmpBN10)

There is nothing to expect from an underdeveloped department. Staff redundancies affected even them. Ironic, isn't it? (EmpBN11)

In a similar vein, a large majority of 'Case B' employees (16 out of 22) argued that HR in general, and learning and development (L\&D) staff in particular, used 
to portray a more enhanced role owing to the adopted business growth strategies back then. However, to date, as senior management dictate business directives, HR's role is limited to their implementation. They further suggested that the limited role of their HR department could also be evidenced through the 'freeze' of their recruitment and selection processes, the wage reductions, the reduced training, etc.:

To date, all decisions are taken from the top and directed through a top-down communication. Then, you are expected to follow them. It is that simple. (EmpBN7)

The HR department's role used to be greater during the sector's prosperous years. Now, its role is supportive rather than a leading one. Its focus has also changed: from people to cost. (EmpCD6)

Some employees (three in total, Case B') offered a more optimistic view though by suggesting that although business restructuring restricted their HR department's role, it did not diminish its importance within the organization, and eventually it is keen to reposition itself as strategic contributor through its value proposition.

Overall, a complex state of HRD executives' role can be noted according to employees' perceptions of it for both periods. Accordingly, SHRD maturity balances between an immature and a mature state according to the period to which employees referred.

Strategic ability to influence and shape business culture and climate

Having discussed that with 'Case A' employees, they highlighted that their organization's culture is weak, as it is not embedded into the way in which the business is run, while its core values are not clearly communicated across all organizational departments and members. They further argued that only within certain functions (e.g. wholesale, retail banking) can a clearer and stronger customer-focused culture be identified. Therefore, they further evaluated business climate as being ineffective in terms of promoting learning and developmental opportunities. Indicatively, an employee argued:

In the past, both (culture \& climate) used to work in favour of the clients rather than the bank; that has totally changed today. The organization now promotes the creation of a business culture of employees' intimidation and uncertainty. (EmpBN12)

'Case B' employees further added that as business objectives are now directed form the top, HR's role in shaping them is limited. However, they have also agreed that, before the crisis, HR held the capacity of indicating future directions and accordingly of shaping business culture and climate in such a way as to lead individual and organizational change, by stating:

Before the crisis, HR philosophy was reflected in our business culture. It was clear that the focus was on enhancing the skills and the capabilities of its people so as to drive the organization forward. (EmpBN8)

Back in the golden years for our sector, a learning-oriented culture, and a supportive business climate, both aimed to promote learning and developmental opportunities to all employees. The message was simple: organizations are their 
people. Today, limited training is offered and not to all employees, while our culture is more cost-efficient oriented. (EmpCD7)

Employees from both banks have also acknowledged that their organizations' cultural values were better circulated in the past and everyone was aware of them so as to incorporate them within his/her work contexts. Yet, today, their organizational cultural values target specific business departments and thus they are clearer to them but not to all employees across the business.

Employees' perceptions outlined HR's ability to influence and shape business culture and climate in the past. However, most employees suggested that their HR department (including their HRD staff) could not impact upon business goals and strategies as everything was 'set from upper management'. Ultimately, a more mature HRD state can be noticed pre- compare to post-crisis.

\section{Emphasis on strategic HRD evaluation}

All research participants (Cases A and B) confirmed that the evaluation of training is typically just limited to the successful completion of the training programmes on behalf of those being trained. It is also remarkable that for a large proportion of employees (33 of 42), the date of their last training was 10-16 months ago or as far back as 4-5 years in some cases. An employee (Case A) stated:

All we need is to get a pass score $(50 \%)$ at the end of the training. That is not difficult as most of the training subjects are general and easy. Whether we have transferred what we have learned does not seem to be a matter of concern though. (EmpBN13)

However, things were different before the crisis. The evaluation of training was a daily on-the-job process focusing on constantly measuring trainees' acquired knowledge and its transfer to their job contexts in order to better contribute to the bottom line. Today, most of the evaluation criteria are relatively short-term oriented, by simply relying on identifying poor performance, or they consist of various qualitative criteria which are very subjective, and eventually making the entire process even more difficult.

Another employee stressed the importance of knowledge transfer to work context:

In the past, we used to closely work with our branch managers right after completing a training course so as to ensure that what was learned was transferred to our daily work routine. (EmpBN14)

'Case B' employees further complained of not been consulted on their actual training needs, nor of being appropriately evaluated. They could not understand how a simple 'pass' on a short questionnaire could constitute a strategic approach to training evaluation. All agreed that even before the crisis, training evaluation was poor by only assess-ing trainees' reaction to training. This is evident through their statements:

There is no systematic way for evaluating training, and the delivery method is not always the best one. That turns the whole process into a waste of time for us and a waste of the bank's resources. (EmpBN9)

Wouldn't it have been better to check if we have transferred what we have 
learned to our jobs? Isn't that more strategic? But, they are the HR experts (laughs) and I guess they know better, don't they? (EmpBN10)

However, what 'Case B' employees did not know was that their behaviour, commitment and satisfaction were closely monitored through mystery customers so that new training needs could be identified and new training programmes could be designed.

Evidently, in both cases, the evaluation of training is conducted in a very functional way. However, drawing upon limited evidence provided on behalf of 'Case B' of organizational documents referring to 'mystery customers', it might be possible to talk of a slightly more mature state compared to 'Case A' in respect of this specific strategic criterion.

\section{Conclusions}

Employees' perceptions of SHRD maturity were collected against a backdrop of their perceptions of the impact of the economic crisis and highlight changes and constraints within the case study organizations over time.

All research participants referred to the impact of the economic crisis upon their organizational practices in general, and HRD in particular. They described its impact as being severe by highlighting its negative aftermath such as the extensive redundancies, pay cuts, increased workloads and full or partial suspension of most HRD-related activities. Therefore, it was not surprising that their perceptions of SHRD maturity out-lined a setback of HRD's role and influence in both organizations.

Employees from both organizations were critical of their HR departments. For all, that was an indication of their direct experience as a 'user' (operational viewpoint). Ultimately, their perceptions were influenced by the lack of access to training and developmental opportunities within their respective organizations. A change to HRD's role and positioning was also noticed with that mainly being perceived through a clear retrenchment approach. Employees (more evident in 'Case A') also appeared sceptical towards HRD's strategic ability in shaping and directing business strategies and goals.

A profound difference was further noticed between the case study organizations concerning their employees' perceptions of HRD's setback. In 'Case A', this was associated with the budgetary constraints and the department's clear short-term focus. In 'Case B', evidence provided on the impact of the economic crisis highlighted a shift from a high-level, consultative, and strategically focused HR department (and that of its HRD staff) to a more reactionary and operationalfocused role. Yet, there were some employees (Case B) who acknowledged that this would probably be transitory due to the latest business amalgamations.

Employees further suggested that HRD had not been silenced nor abandoned, yet its activities were highly restricted compared to pre-crisis. Their suggestions also focused on HRD's short-term/operational role and its lack of influence throughout the restructuring process, either through leading or through managing change. Eventually, that restricted HRD's value proposition; an essential element to re-establish a strong organizational presence within the banking sector. Precisely, 'Case A' employees argued that the impact of the crisis resulted in the creation of an under-developed business function, which lacked the necessary competencies to help them manage business uncertainty and complexity. Accordingly, 'Case B' employees have questioned HRD's legitimacy and credibility because of the department's starved resources (due to limited budget 
allocations and the transition period of the banking sector).

Employees raised concerns as to the capability of their HR departments (and the role of its HRD executives) in the crisis context. Contrary to the literature's suggestions that HRD could contribute to organizational effectiveness and longterm success, in the main, research findings suggest that SHRD maturity in 'Case A' was evidenced at a lower base compared to 'Case B'. Taking everything into consideration, a research question may be raised as to the extent to which a case for SHRD maturity could be present in such contexts.

Overall, the study raised important questions for both HRD academics and practitioners due to the HRD setback that was observed. Whilst employees' perceptions of this were mixed, they mostly presented SHRD as a rhetorical notion rather than some-thing that was really happening within their organizations. The researcher is left with a sense that HRD did not manage to respond influentially to the organizational challenges brought on by the crisis. SHRD remained an organizational aspiration, and thus its ability to drive both organizations forward in times of continued operating and financial difficulties (post-crisis) was highly questioned. In total, the economic crisis had mostly been seen as an obstacle to HRD's capacity rather than as an opportunity to demonstrate its potential.

However, it is important to acknowledge that all considerations were based on employees' perceptions of SHRD maturity within the case study banking organizations. Ultimately, that may not constitute a general outcome for the HRD function in organizations facing similar problems. Yet, perceptions remain crucial. This needs careful consideration. The research findings that emerged are dependent on the research participants' perceptions of the examined situation several years ago. In any case, though, it is important to highlight that in order to achieve the intended organizational objectives, not only are the right HRD practices required, but also the shared and aligned employees' perceptions of those practices are needed. And that was the aim of this research study.

\section{Limitations and recommendations for future research}

Given this research's focus on only two Greek banks, the sample was restricted and ultimately its findings may be limited to those organizations. Possibly they may be applicable to the banking sector, or to other similar industries in Greece. Therefore, the research findings cannot be generalized to an international context due to different organizational and social contexts (e.g. political, economic, etc.). However, someone may equally argue that they can be applicable to those sectors and nations facing similar problems to Greece. In that case, future research will benefit from a comparison amongst bank institutions between two or more countries operating under similar business and economic circumstances. Future research would benefit from the replication of this study in other countries and/or organizations/industries facing or having faced similar problems so as to offer additional insights into how HRD could fulfil its strategic aspirations, especially under the challenging context of an economic crisis.

A second limitation derives from both organizations' refusal to allow the researcher to conduct interviews with their top management executives, along with a lack of access to the Hellenic Bank Association (HBA) and trade union representatives. All stakeholders are considered crucial in providing relevant information on banks' HRD strategies and for both periods for a holistic comparison to take place. However, it was difficult to approach senior managers 
due to their workload, while trade union and HBA representatives were excluded due to time constraints; instead, a few unionized employees were interviewed. Therefore, future research would benefit from the inclusion of all potential stakeholders so as to grasp their perspectives, and thus to offer a more holistic understating of the examined topic.

Thirdly, a methodological limitation relates to the research sample of the study and the researcher's decision not to approach all banks (5 in total) within the sector. However, due to time constraints, a longitudinal study was not possible. Future research, either within the Greek territory or elsewhere, would benefit from the examination of the entire sector for deeper insights to be drawn.

Finally, there are some limitations associated with the employment of a retrospective design (e.g. interviewees' responses tend to be biased towards change and sensitive issues, difficulties in recalling past events which may lead to poor-quality data, whether interviewees have or do not have knowledge of past events, etc.). Although a longitudinal study may appear a suitable alternative method, it was difficult for this to be undertaken due to time constraints, and the refusal of the case study banking organizations to commit their staff for more than a few days. To overcome these 'research constraints', the researcher carefully selected his interview sample to consist of key individuals employed for more than 6 years within their organization. All research participants held the appropriate knowledge to address interview questions at a pre- and post-crisis assessment approach. In addition, the researcher posed them many probing questions in order to facilitate discussion and to help them recall past events.

\section{References}

Becker, E. B., Huselid, A. M. and Ulrich, D. (2001), The HR Scorecard; Linking People, Strategy, and Performance (Boston, MA: Harvard Business School Press).

Boudreau, J. and Ramstad, P. (2004), 'Talent-ship, talent segmentation and sustainability: a new HR decision science paradigm for a new strategy definition', Human Resource Management, 44, 2, 129-36.

Cascio, W. F. (2014), 'Investing in HRD in uncertain times now and in the future', Advances in Developing Human Resources, 16, 1, 108-22.

Chuang, S.-H. and Lin, H.-N. (2016), 'Performance implications of informationvalue offering in e-service systems: examining the resource-based perspective and innovation strategy', Journal of Strategic Information Systems, 26, 1, $22-$ 38.

Dwyer, T. D. (2000). 'The elusive match: building a strategic partnership between HR and business', International HR Journal, 9, 35-41.

Felstead, A., Green, F. and Jewson, N. (2012), The impact of the 2008-2009 recession on training at work. Briefing Paper, May 2012, First Interim Report from February 2010 to September 2010. UK Commission for Employment and Skills, UKCES, Wath upon Dearne, Rotherham, UK, pp. 1-34.

Fiksel, J. (2015), Resilient by Design: Creating Businesses that Adapt and Flourish in a Changing World (Washington, DC: Island Press).

Garavan, T. N. (1991), 'Strategic human resource development', Journal of European Industrial Training, 15, 1, 17-30.

Garavan, T. N. (2007), 'A strategic perspective on human resource development', Advances in Developing Human Resources, 9, 1, 11-30.

Garavan, T. N., Shanahan, V., Carbery, R. and Watson, S. (2016), 'Strategic 
human resource development: towards a conceptual framework to understand its contribution to dynamic capabilities', Human Resource Development International, 19, 4, 289-306.

Gilley, W. J. and Gilley, A. M. (2003), Strategically Integrated HRD: Six Transformational Roles in Creating Results-Driven Programs, 2nd edn (Cambridge, MA: Perseus Publishing).

Gilley, W. J. and Maycunich, A. (2000a), Organizational Learning, Performance, and Change: An Introduction to Strategic Human Resource Development (Cambridge, MA: Perseus Publishing).

Gilley, W. J. and Maycunich, A. (2000b), Beyond the Learning Organization: Creating a Culture of Continuous Development through State-of-the-Art Human Resource Practices (Cambridge, MA: Perseus Publishing).

Holbeche, L. (2009), Aligning Human Resources and Business Strategy, 2nd edn (Oxford: Butterworth Heinemann).

Lee, R. (1996), 'The pay forward view of training', People Management, 2, 3, 3032.

MacKenzie, C. A., Garavan, T. N. and Carbery, R. (2012), 'Through the looking glass: challenges for human resource development (HRD) post the global financial crisis - business as usual?', Human Resource Development International, 15, 3, 353-64.

MacKenzie, C. A., Garavan, T. N. and Carbery, R. (2014), 'The global financial and economic cri-sis: did HRD play a role?', Advances in Developing Human Resources, 16, 1, 34-50.

Marchington, M. and Grugulis, I. (2000), "Best practice" human resource management: perfect opportunity or dangerous illusion?', International Journal of Human Resource Management, 11, 6, 1104-24.

McCarthy, A. and Sheehan, M. (2014), 'Uncertainty and ongoing economic turbulence: Implications for HRD', Advances in Developing Human Resources, $16,1,3-12$.

McCracken, M. and Wallace, M. (2000a), 'Towards a redefinition of strategic HRD', Journal of European Industrial Training, 24, 5, 281-90.

McCracken, M. and Wallace, M. (2000b), 'Exploring strategic maturity in HRDrhetoric, aspiration or reality?', Journal of European Industrial Training, 24, 8, 425-67.

Mitsakis, F. (2014a), 'The impact of economic crisis in Greece: key facts and an overview of the banking sector', Business and Economic Research, 4, 1, 248 65.

Mitsakis, F. (2014b), 'Human resources (HR) as a strategic business partner: value creation and risk reduction capacity', International Journal of Human Resource Studies, 4, 1, 154-70.

Mitsakis, F. and Aravopoulou, E. (2016), 'The impact of the economic crisis upon human resource development (HRD): evidence from two Greek banks', International Journal of Human Resource Development Practice, Policy and Research, 1, 2, 67-82.

Pfeffer, J. (1998), 'The real keys to high performance', Leader to Leader, 1998, 8, 23-7.

Robinson, D. G. and Robinson, J. C. (2005), Strategic Business Partner (San Francisco, CA: Berrett-Koehler).

Sung, Y. S. and Choi, N. J. (2013), 'Do organizations spend wisely on employees? Effects of train-ing and development investments on learning and innovation in organizations', Journal of Organizational Behaviour, 35, 3, 393-412.

Torraco, R. J. and Swanson, R. A. (1995). 'The strategic roles of human resource development'. Human Resource Planning, 18, 4, 10-21. 
Ulrich, D. (1998), 'A new mandate for human resources', Harvard Business Review, 76, 1, 123-34.

Valentin, C. (2006), 'Researching human resource development: emergence of a critical approach to HRD enquiry', International Journal of Training and Development, 10, 1, 17-29. 